\title{
Impact of long-term air pollution exposure on metabolic control in children and adolescents with type 1 diabetes: results from the DPV registry
}

\author{
Stefanie Lanzinger ${ }^{1,2}$ (D) Joachim Rosenbauer ${ }^{2,3} \cdot$ Dorothea Sugiri $^{4} \cdot$ Tamara Schikowski $^{4} \cdot$ Birgit Treiber $^{5} \cdot$ \\ Daniela Klee ${ }^{6}$. Wolfgang Rathmann ${ }^{2,3} \cdot$ Reinhard W. Holl ${ }^{1,2}$
}

Received: 24 August 2017 / Accepted: 30 January 2018 / Published online: 24 February 2018

(C) Springer-Verlag GmbH Germany, part of Springer Nature 2018

\begin{abstract}
Aims/hypothesis Studies on the association between air pollution and metabolic control in children and adolescents with type 1 diabetes are rare and findings are inconsistent. We examined the relationship between air pollution variables (particulate matter with an aerodynamic diameter $<10 \mu \mathrm{m}\left[\mathrm{PM}_{10}\right], \mathrm{NO}_{2}$ and accumulated ozone exposure $\left[\mathrm{O}_{3}\right.$-AOT]) and metabolic variables $\left(\mathrm{HbA}_{1 \mathrm{c}}\right.$ and daily insulin dose [U/kg body weight]) in children and adolescents with type 1 diabetes.

Methods We investigated 37,372 individuals with type 1 diabetes aged <21 years, documented between 2009 and 2014 in 344 German centres of the prospective diabetes follow-up registry (Diabetes-Patienten-Verlaufsdokumentation [DPV]). Long-term air pollution exposure (annual and quinquennial means) data were linked to participants via the five-digit postcode areas of residency. Cross-sectional multivariable regression analysis was used to examine the association between air pollution and metabolic control.

Results After comprehensive adjustment, an interquartile range increase in $\mathrm{O}_{3}$-AOT was associated with a lower $\mathrm{HbA}_{1 \mathrm{c}}(-3.7 \%$ [95\% CI $-4.4,-3.0]$ ). The inverse association between $\mathrm{O}_{3}$ - $\mathrm{AOT}$ and $\mathrm{HbA}_{1 \mathrm{c}}$ persisted after additional adjustment for degree of urbanisation or additional adjustment for $\mathrm{PM}_{10}$. Moreover, the inverse association remained stable in further sensitivity analyses. No significant associations between $\mathrm{HbA}_{1 \mathrm{c}}$ and $\mathrm{PM}_{10}$ or $\mathrm{NO}_{2}$ were found. No association was observed between any of the three air pollutants and insulin dose.

Conclusions/interpretation The inverse association between $\mathrm{O}_{3}$-AOT and $\mathrm{HbA}_{1 \mathrm{c}}$ could not be explained by regional differences in diabetes treatment or by other differences between urban and rural areas. Furthermore, our results remained stable in sensitivity analyses. Further studies on the association between air pollution and $\mathrm{HbA}_{1 \mathrm{c}}$ in children and adolescents with type 1 diabetes are needed to confirm our observed association and to elucidate underlying mechanisms.
\end{abstract}

Keywords Air pollution $\cdot \mathrm{HbA}_{1 \mathrm{c}} \cdot$ Insulin $\cdot$ Metabolic control $\cdot$ Ozone $\cdot$ Particulate matter $\cdot$ Type 1 diabetes

Stefanie Lanzinger and Joachim Rosenbauer contributed equally to this study.

Electronic supplementary material The online version of this article (https://doi.org/10.1007/s00125-018-4580-8) contains peer-reviewed but unedited supplementary material, which is available to authorised users.

Stefanie Lanzinger

stefanie.lanzinger@uni-ulm.de

1 Institute of Epidemiology and Medical Biometry, Central Institution for Biomedical Engineering (ZIBMT), University of Ulm, Albert-Einstein-Allee 41, 89081 Ulm, Germany

2 German Centre for Diabetes Research (DZD), München, Neuherberg, Germany
3 Institute for Biometrics and Epidemiology, German Diabetes Centre, Leibniz Centre for Diabetes Research at Heinrich Heine University Düsseldorf, Düsseldorf, Germany

4 Leibniz Research Institute for Environmental Medicine (IUF), Düsseldorf, Germany

5 Hospital for Children and Adolescents, Clinical Centre St Marien, Amberg, Germany

6 Pediatric Practice, Bürstadt, Germany 


\section{Research in context}

\section{What is already known about this subject?}

- Previous studies have shown an association between air pollution and $\mathrm{HbA}_{1 c}$ in adults with type 2 diabetes

- Only few studies have focused on the impact of air pollution on children and adolescents with type 1 diabetes

\section{What is the key question?}

- Is there an association between long-term exposure to air pollution and metabolic control in children and adolescents with type 1 diabetes?

\section{What are the new findings?}

- Results of the prospective diabetes follow-up registry (Diabetes-Patienten-Verlaufsdokumentation [DPV]) showed that lower $\mathrm{HbA}_{1 c}$ was associated with increased long-term ozone exposure

- The inverse association between $\mathrm{HbA}_{1 c}$ and ozone remained stable in sensitivity analyses

- $\quad$ No association was observed between particulate matter or $\mathrm{NO}_{2}$ and $\mathrm{HbA} A_{1 c}$

\section{How might this impact on clinical practice in the foreseeable future?}

- In addition to the factors that can be influenced by an individual with type 1 diabetes, such as treatment compliance, environmental factors that might have an impact on $\mathrm{HbA}_{1 c}$ need to be considered in diabetes care

\begin{tabular}{|c|c|}
\hline \multicolumn{2}{|c|}{ Abbreviations } \\
\hline $25(\mathrm{OH}) \mathrm{D}$ & 25-Hydroxyvitamin D \\
\hline DPV & Diabetes-Patienten-Verlaufsdokumentation \\
\hline IQR & Interquartile range \\
\hline KiGGS & $\begin{array}{l}\text { German Health Interview and Examination } \\
\text { Survey for Children and Adolescents }\end{array}$ \\
\hline KORA & $\begin{array}{l}\text { Cooperative Health Research in the Region } \\
\text { of Augsburg, Germany }\end{array}$ \\
\hline $\mathrm{O}_{3}-\mathrm{AOT}$ & Accumulated ozone exposure \\
\hline $\mathrm{PM}_{10}$ & $\begin{array}{l}\text { Particulate matter with an aerodynamic } \\
\text { diameter }<10 \mu \mathrm{m}\end{array}$ \\
\hline SDS & Standard deviation score \\
\hline
\end{tabular}

\section{Introduction}

Most epidemiological studies investigating the association between air pollution and diabetes have so far focused on type 2 diabetes mellitus in adults. Studies reported an increased risk of type 2 diabetes with long-term exposure to air pollution $[1,2]$. Moreover, individuals with diabetes have been shown to be especially susceptible to the adverse health effects of air pollution [3, 4]. Biological mechanisms explaining the cardiovascular effects in individuals with diabetes in response to air pollution include systemic oxidative stress and inflammation, further leading to changes in the vascular endothelium and changes in metabolism such as impaired insulin sensitivity $[2,5,6]$. The $\mathrm{HbA}_{1 \mathrm{c}}$ level reflects the average plasma glucose concentration over 3 months and is an important marker of metabolic control [7]. Moreover, $\mathrm{HbA}_{1 \mathrm{c}}$ has been shown to be a predictor for diabetes complications [7]. In a previous study, the association between ambient air particulate matter with an aerodynamic diameter $<10 \mu \mathrm{m}$ $\left(\mathrm{PM}_{10}\right)$ and $\mathrm{HbA}_{1 \mathrm{c}}$ in adults with type 2 diabetes was examined [8]. The authors reported significantly higher $\mathrm{HbA}_{1 \mathrm{c}}$ with higher $\mathrm{PM}_{10}$ exposure. Recently, increased $\mathrm{HbA}_{1 \mathrm{c}}$ levels were found to be associated with an increase in the 3 month $\mathrm{PM}_{10}$ average (intermediate-term exposure) in individuals with diabetes but no such association was seen for an increase in the 1-7 day $\mathrm{PM}_{10}$ exposure (short-term exposure) [9].

Studies on air pollution and type 1 diabetes mellitus in children and adolescents are rare. A recent study investigated the long-term effects of $\mathrm{PM}_{10}, \mathrm{NO}_{2}$ (annual means) and accumulated ozone exposure $\left(\mathrm{O}_{3}\right.$-AOT, quinquennial means) on $\mathrm{HbA}_{1 \mathrm{c}}$ in 771 children and adolescents with type 1 diabetes [10]. Individuals with early-onset type 1 diabetes, aged 1121 years, from a nationwide population-based diabetes registry of the German Diabetes Centre, Düsseldorf(DDZ registry) were included in the study. No adverse effects of $\mathrm{PM}_{10}, \mathrm{NO}_{2}$ or $\mathrm{O}_{3}$-AOT on $\mathrm{HbA}_{1 \mathrm{c}}$ were found. However, the authors reported an unexpected inverse association between $\mathrm{O}_{3}$-AOT and $\mathrm{HbA}_{1 \mathrm{c}}$, showing a decrease in $\mathrm{HbA}_{1 \mathrm{c}}$ (regression estimate $-1.5[95 \% \mathrm{CI}-2.8,-0.2])$ in association with an interquartile range (IQR) increase in $\mathrm{O}_{3}$-AOT. However, the association was not robust in all sensitivity analyses performed. A nonsignificant inverse association between long-term exposure to $\mathrm{O}_{3}$ and $\mathrm{HbA}_{1 \mathrm{c}}$ was also reported in a nationwide study of 11,847 adults in China [11]. 
A previous study emphasised the importance of studying the association between air pollution and metabolic control in children and adolescents with type 1 diabetes in a larger cohort [10]. The aim of our work was to conduct a large-scale study including all children and adolescents with type 1 diabetes documented in German centres of the prospective diabetes follow-up registry (DiabetesPatienten-Verlaufsdokumentation [DPV]) and to examine the impact of $\mathrm{PM}_{10}, \mathrm{NO}_{2}$ and $\mathrm{O}_{3}$-AOT on indicators of metabolic control $\left(\mathrm{HbA}_{1 \mathrm{c}}\right.$ and insulin dose).

\section{Methods}

Measurement of air pollutants The German Federal Environmental Agency (Umweltbundesamt [UBA] FG II 4.2) provided air pollution background measures for Germany which were derived by dispersion modelling using the chemical REM-CALGRID model and smoothed by the method of optimal interpolation (as described elsewhere [10]). Concentrations of $\mathrm{PM}_{10}, \mathrm{NO}_{2}, \mathrm{O}_{3}$, and $\mathrm{O}_{3}$ AOT over a threshold of $80 \mu \mathrm{g} / \mathrm{m}^{3}$ were available in $7 \mathrm{~km} \times 8 \mathrm{~km}$ raster cells for the whole of Germany. For each air pollutant, an area-weighted mean per five-digit postcode area was calculated by intersection of the $7 \times 8 \mathrm{~km}^{2}$ raster with the German postcode map using ArcGIS (version 10; Environmental Systems Research Institute [ESRI], Redlands, CA, USA) [10]. The Directive 2008/50/EC of the European Parliament defines limit values for annual means of $\mathrm{PM}_{10}$ and $\mathrm{NO}_{2}$, whereas target values for $\mathrm{O}_{3}$-AOT are averaged over 5 years [12]. Therefore, annual means for the years 2009-2014 were used for $\mathrm{PM}_{10}$ and $\mathrm{NO}_{2}$ and quinquennial means (20052009 to 2010-2014) were used for $\mathrm{O}_{3}$-AOT in the analyses. To define $\mathrm{O}_{3}$-AOT, for all values between 08:00 hours and 20:00 hours exceeding a threshold of $\geq 80 \mu \mathrm{g} / \mathrm{m}^{3}$, the difference to this threshold was determined. Therefore, $\mathrm{O}_{3}$-AOT is defined as the sum of these differences between $1 \mathrm{~h}$ means $\geq 80 \mu \mathrm{g} / \mathrm{m}^{3}$ from May to July and averaged over 5 years [13].

Participants and data The DPV registry is a multicentre, prospective survey of routinely collected data for all types of diabetes [14]. DPV registry data are used for quality control and diabetes research. Information is collected during routine examinations and includes demographic and anthropometric characteristics, diabetes therapy, comorbidities and disease outcomes related to diabetes. To date, DPV comprises 454 participating centres predominantly in Germany (412 centres). Of these, 344 centres in Germany provided data for the underlying analysis. Semiannually, anonymised data were sent to Ulm University for validation and analyses. Data collection and analysis were approved by the ethics committee of Ulm University as well as by the local review boards of the participating centres. Corresponding to the period of air pollutant measurements, individuals with type 1 diabetes documented in German DPV centres between 2009 and 2014 and aged $<21$ years were selected for the analysis. Participants $<6$ months of age at diabetes onset were excluded.

Demographic and clinical data extracted from the DPV register were sex, age, diabetes duration, migration background (at least one parent not born in Germany), year of treatment, BMI $\left(\mathrm{kg} / \mathrm{m}^{2}\right)$, type of insulin treatment (conventional insulin therapy, $\leq 3$ injections per day; intensive insulin therapy, 4-8 injections per day or insulin pump), $\mathrm{HbA}_{1 \mathrm{c}}(\%$ or $\mathrm{mmol} / \mathrm{mol})$ and daily insulin dose $(\mathrm{U} / \mathrm{kg}$ body weight). The standard deviation score (SDS) for BMI was calculated based on reference data from the German Health Interview and Examination Survey for Children and Adolescents (KiGGS) [15]. SDS values indicate the SD below or above a reference value [15]. Based on BMI, weight status was categorised into underweight/normal weight $(\mathrm{BMI} \leq 90$ th percentile), overweight (BMI $>90$ th and $\leq 97$ th percentile) or obesity (BMI > 97th percentile) using national reference data from KiGGS [15]. The multiple of the mean transformation method was used to standardise $\mathrm{HbA}_{1 \mathrm{c}}$ values to the DCCT reference range of $20.7-42.6 \mathrm{mmol} / \mathrm{mol}(4.05-$ $6.05 \%$ ) to account for different laboratory methods [16]. For each participant, demographic and clinical data of the most recent treatment year in the period 2009-2014 were selected and aggregated (median) before analyses. Therefore, the outcomes $\mathrm{HbA}_{1 \mathrm{c}}$ and daily insulin dose were related to $\mathrm{PM}_{10}$ and $\mathrm{NO}_{2}$ annual means for the respective most recent treatment year per participant. For $\mathrm{O}_{3}$-AOT, the average over the 5 years preceding the most recent treatment year was examined (e.g. if the most recent treatment year was 2012, clinical data from 2012 were aggregated and associated with $\mathrm{O}_{3}$-AOT exposure data from 2008-2012). Exposure data were linked to participants via the five-digit postcodes of participants' residency. We used the concept of Nielsen areas to account for regional differences, as described elsewhere [10]. The seven German Nielsen areas are presented in the electronic supplementary material (ESM) Methods section.

In a sensitivity analysis, we additionally adjusted for degree of urbanisation. We differentiated three degrees of urbanisation (urban centres, town or suburb and rural areas) based on the population density of local administrative units as provided by Eurostat [17] and as described elsewhere [10].

Statistical analyses Results of descriptive analyses are presented as median (IQR) for continuous variables and proportions for categorical variables. Spearman's rank correlation 
coefficient was used to calculate associations between air pollutants. Multivariable linear regression models were used to investigate the association between air pollutants as independent variables and $\mathrm{HbA}_{1 \mathrm{c}}$ or insulin dose as dependent outcomes. $\mathrm{PM}_{10}, \mathrm{NO}_{2}$ and $\mathrm{O}_{3}$-AOT were included in the model as a continuous variable. Results are presented as per cent changes in outcome means per IQR increase in the respective air pollutant together with $95 \% \mathrm{CI}$ (per cent change $=\mathrm{IQR} \times$ regression estimate $\times 100$ /outcome mean). Main models were adjusted for sex, age ( $\leq 5$ years, $>5-10$ years, $>10-15$ years, $>15-20$ years), diabetes duration ( $<2$ years, $\geq 2$ years), migration background, year of treatment, type of insulin treatment and Nielsen area. When analysing the association between air pollutants and insulin dose, we additionally adjusted for weight status.

In additional regression analyses, $\mathrm{O}_{3}-\mathrm{AOT}$ was categorised into four quartiles (Q1-Q4: Q1, <10,433 $\mu \mathrm{g} / \mathrm{m}^{3} \times \mathrm{h} ; \mathrm{Q} 2,10,433$ to $<12,878 \mu \mathrm{g} / \mathrm{m}^{3} \times \mathrm{h} ;$ Q3, 12,878 to $<15,346 \mu \mathrm{g} / \mathrm{m}^{3} \times \mathrm{h} ; \mathrm{Q} 4, \geq 15,346 \mu \mathrm{g} / \mathrm{m}^{3} \times \mathrm{h}$ ), with the highest quartile used as reference group.
Regression results for air pollution quartiles are presented as adjusted least-square means together with $95 \% \mathrm{CI}$ estimated from regression models using observed marginal distributions of covariates.

To test the robustness of our results regarding $\mathrm{O}_{3}$-AOT, we conducted various sensitivity analyses: (1) we fitted models without adjusting for Nielsen areas; (2) Nielsen areas were included as a random intercept into the models using the variance components covariance structure; (3) instead of Nielsen areas, the centre was included as a random intercept; (4) we additionally adjusted for degree of urbanisation; (5) we additionally adjusted for $\mathrm{PM}_{10}$ when analysing the association between $\mathrm{O}_{3}$-AOT and $\mathrm{HbA}_{1 \mathrm{c}}$; (6) since residuals for $\mathrm{HbA}_{1 \mathrm{c}}$ deviated from normality, we performed sensitivity analyses using log-transformed $\mathrm{HbA}_{1 \mathrm{c}}$; (7) we investigated the association between annual means of $\mathrm{O}_{3}$ and $\mathrm{HbA}_{1 \mathrm{c}}$ and insulin dose; and (8) natural cubic regression splines were used to check linearity of the dose-response function. The number of knots was selected by minimising Akaike's information criterion.
Table 1 Characteristics of individuals with type 1 diabetes $(n=37,372)$ and description of air pollutants

\begin{tabular}{|c|c|}
\hline Characteristic & Type 1 diabetes \\
\hline Age, years & $14.7(6.4)$ \\
\hline Age at diabetes onset, years & $8.3(6.9)$ \\
\hline Diabetes duration, years & $4.8(6.5)$ \\
\hline Weight SDS & $0.3(1.2)$ \\
\hline Height SDS & $0.1(1.4)$ \\
\hline BMI SDS & $0.3(1.1)$ \\
\hline $\left.\mathrm{HbA}_{1 \mathrm{c}}, \mathrm{mmol} / \mathrm{mol}\right)$ & $61.5(20.7)$ \\
\hline $\mathrm{HbA}_{1 \mathrm{c}}, \%$ & $7.8(1.9)$ \\
\hline No. of $\mathrm{HbA}_{1 \mathrm{c}}$ measurements/participant & $4.0(2.0)$ \\
\hline Daily insulin dose, $\mathrm{U} / \mathrm{kg}$ & $0.8(0.3)$ \\
\hline Number of insulin dose measurements/participant & $4.0(2.0)$ \\
\hline Number of glucose self-monitoring measurements per day & $5.0(2.5)$ \\
\hline Treatment year & $2014(2)$ \\
\hline Male sex & 52.8 \\
\hline CT (1-3 injections/day) & 3.9 \\
\hline ICT (4-8 injections/day) & 54.2 \\
\hline Insulin pump & 41.9 \\
\hline Migration background ${ }^{\mathrm{a}}$ & 18.8 \\
\hline \multicolumn{2}{|l|}{ Air pollutant $\mathrm{t}^{\mathrm{b}}$} \\
\hline $\mathrm{PM}_{10}, \mu \mathrm{g} / \mathrm{m}^{3}$ & $17.7(3.5)$ \\
\hline $\mathrm{NO}_{2}, \mu \mathrm{g} / \mathrm{m}^{3}$ & $15.0(7.4)$ \\
\hline $\mathrm{O}_{3}, \mu \mathrm{g} / \mathrm{m}^{3}$ & $48.7(6.9)$ \\
\hline $\mathrm{O}_{3}$-AOT, $\mu \mathrm{g} / \mathrm{m}^{3} \times \mathrm{h}$ & $12,878.1(4912.5)$ \\
\hline
\end{tabular}

Data are presented as median (IQR) or $n \%$

${ }^{\mathrm{a}}$ At least one parent not born in Germany

${ }^{\mathrm{b}}$ Average exposure for the study population

$\mathrm{CT}$, conventional insulin therapy; ICT, intensive insulin therapy 
Table 2 Association between long-term air pollution exposure and $\mathrm{HbA}_{1 \mathrm{c}}$

\begin{tabular}{|c|c|c|c|}
\hline Air pollutant and model & IQR & Per cent change $^{\mathrm{a}}(95 \% \mathrm{CI})$ & $p$ value \\
\hline \multicolumn{4}{|l|}{$\mathrm{PM}_{10}$} \\
\hline Main model ${ }^{\mathrm{b}}$ & 3.5 & $0.1(-0.3,0.6)$ & 0.524 \\
\hline Without Nielsen area & 3.5 & $1.4(1.1,1.8)$ & $<0.001$ \\
\hline Nielsen area as random effect & 3.5 & $0.2(-0.3,0.6)$ & 0.432 \\
\hline Centre as random effect & 3.5 & $0.8(0.3,1.4)$ & 0.001 \\
\hline Main model+degree of urbanisation & 3.5 & $0.1(-0.4,0.5)$ & 0.802 \\
\hline Outcome log-transformed & 3.5 & $0.1(-0.3,0.5)$ & 0.484 \\
\hline \multicolumn{4}{|l|}{$\mathrm{NO}_{2}$} \\
\hline Main model ${ }^{\mathrm{b}}$ & 7.4 & $-0.3(-0.8,0.1)$ & 0.157 \\
\hline Without Nielsen area & 7.4 & $-0.5(-0.9,-0.1)$ & 0.025 \\
\hline Nielsen area as random effect & 7.4 & $-0.3(-0.8,0.1)$ & 0.155 \\
\hline Centre as random effect & 7.4 & $0.3(-0.2,0.8)$ & 0.277 \\
\hline Main model+degree of urbanisation & 7.4 & $-0.7(-1.3,-0.2)$ & 0.007 \\
\hline Outcome log-transformed & 7.4 & $-0.3(-0.7,0.1)$ & 0.112 \\
\hline \multicolumn{4}{|l|}{$\mathrm{O}_{3}$-AOT } \\
\hline Main model ${ }^{\mathrm{b}}$ & 4912.5 & $-3.7(-4.4,-3.0)$ & $<0.001$ \\
\hline Without Nielsen area & 4912.5 & $-2.6(-3.1,-2.2)$ & $<0.001$ \\
\hline Nielsen area as random effect & 4912.5 & $-3.7(-4.4,-2.9)$ & $<0.001$ \\
\hline Centre as random effect & 4912.5 & $-2.1(-3.0,-1.2)$ & $<0.001$ \\
\hline Main model+degree of urbanisation & 4912.5 & $-3.7(-4.4,-3.0)$ & $<0.001$ \\
\hline Main model $+\mathrm{PM}_{10}$ & 4912.5 & $-3.8(-4.5,-3.0)$ & $<0.001$ \\
\hline Outcome log-transformed & 4912.5 & $-3.5(-4.1,-2.8)$ & $<0.001$ \\
\hline \multicolumn{4}{|l|}{$\mathrm{O}_{3}$} \\
\hline Main model ${ }^{\mathrm{b}}$ & 6.9 & $-0.8(-1.3,-0.4)$ & $<0.001$ \\
\hline Without Nielsen area & 6.9 & $-1.1(-1.5,-0.7)$ & $<0.001$ \\
\hline Nielsen area as random effect & 6.9 & $-0.8(-1.3,-0.4)$ & $<0.001$ \\
\hline Centre as random effect & 6.9 & $-0.9(-1.4,-0.4)$ & $<0.001$ \\
\hline Main model+degree of urbanisation & 6.9 & $-0.9(-1.4,-0.4)$ & $<0.001$ \\
\hline Main model+PM 10 & 6.9 & $-1.2(-1.7,-0.6)$ & $<0.001$ \\
\hline Outcome log-transformed & 6.9 & $-0.8(-1.2,-0.4)$ & $<0.001$ \\
\hline
\end{tabular}

${ }^{a}$ Per cent change in $\mathrm{HbA}_{1 \mathrm{c}}=\mathrm{IQR} \times$ regression estimate $\times 100 /$ outcome mean

${ }^{\mathrm{b}}$ Adjusted for sex, age, diabetes duration, migration background, year of treatment, type of insulin therapy and Nielsen area
Statistical analyses were conducted using SAS version 9.4 (SAS Institute, Cary, NC, USA). A two-sided $p$ value $<0.05$ was considered as statistically significant.

\section{Results}

As of March 2016, 108,052 individuals diagnosed with type 1 diabetes were registered in German DPV centres. Of these individuals, 74,751 were $<21$ years of age and 42,993 were documented between 2009 and 2014. The study population consisted of 37,372 participants (from 344 German centres) for whom information was available on $\mathrm{HbA}_{1 \mathrm{c}}$, daily insulin dose, five-digit postcode and air pollution of residence.
The median age of individuals with type 1 diabetes was 14.7 years $(53 \%$ male sex, Table 1$)$. The median $\mathrm{HbA}_{1 \mathrm{c}}$ was $61.5 \mathrm{mmol} / \mathrm{mol}(7.8 \%)$ and median daily insulin dose was $0.8 \mathrm{U} / \mathrm{kg}$. $\mathrm{HbA}_{1 \mathrm{c}}$ and insulin dose were measured about four times per participant during the most recent treatment year. The median most recent treatment year of the study population was 2014. Most of the participants were treated with intensive insulin therapy $(54.2 \%)$ followed by insulin pump (41.9\%). Around $20 \%$ of the study population had a migration background.

A basic description of the distribution of air pollutants and Spearman's rank correlation coefficients are presented in ESM Tables 1 and 2. We observed a decrease in $\mathrm{PM}_{10}, \mathrm{NO}_{2}$ and $\mathrm{O}_{3-}$ - 


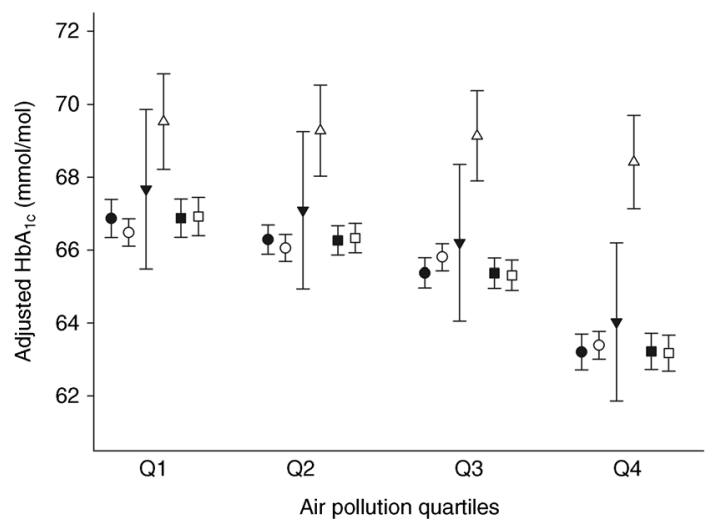

Fig. 1 Adjusted $\mathrm{HbA}_{1 \mathrm{c}}$ (mean and 95\% CI) by $\mathrm{O}_{3}$-AOT quartiles. Black circles, main model adjusted for sex, age, diabetes duration, migration background, year of treatment, type of insulin treatment and Nielsen area; white circles, no adjustment for Nielsen area; black triangles, Nielsen area as random effect; white triangles, centre as random effect; black squares, additional adjustment for degree of urbanisation; white squares, additional adjustment for $\mathrm{PM}_{10}$ quartile. Q1, $<10,433 \mu \mathrm{g} / \mathrm{m}^{3} \times$ $\mathrm{h}$; Q2, 10,433 to $<12,878 \mu \mathrm{g} / \mathrm{m}^{3} \times \mathrm{h}$; Q3, 12,878 to $<15,346 \mu \mathrm{g} / \mathrm{m}^{3} \times \mathrm{h}$; Q4, $\geq 15,346 \mu \mathrm{g} / \mathrm{m}^{3} \times \mathrm{h}$

AOT averages from 2009 to 2014, with small fluctuations between the years (ESM Table 1). There was a moderate correlation between $\mathrm{PM}_{10}$ and $\mathrm{NO}_{2}$ (Spearman's rank correlation coefficient $r_{\mathrm{s}}=0.5$ [ESM Table 2]). The correlation between $\mathrm{PM}_{10}$ and $\mathrm{O}_{3}$-AOT and between $\mathrm{NO}_{2}$ and $\mathrm{O}_{3}$-AOT was low with $\left|r_{\mathrm{s}}\right| \leq 0.1$.

A description of data by Nielsen area is shown in ESM Table 3. The highest $\mathrm{HbA}_{1 \mathrm{c}}$ values were observed in Berlin and the Northeast area and the lowest were seen in the East. Daily insulin dose was comparable across all regions. Berlin showed the highest $\mathrm{PM}_{10}$ concentrations compared with the other areas. $\mathrm{NO}_{2}$ was highest in Berlin and the West. The lowest $\mathrm{PM}_{10}$ levels were found in the South and the lowest $\mathrm{NO}_{2}$ levels were observed in the Northeast. Five-year averages of $\mathrm{O}_{3}$-AOT were highest in the Southwest and lowest in the North.

Table 2 shows the association between long-term air pollution exposure and $\mathrm{HbA}_{1 \mathrm{c}}$. We observed a significant inverse association between $\mathrm{O}_{3}$-AOT and $\mathrm{HbA}_{1 \mathrm{c}}$. $\mathrm{HbA}_{1 \mathrm{c}}$ decreased by $3.7 \%(95 \% \mathrm{CI}-4.4,-3.0)$ with an IQR increase in $\mathrm{O}_{3}$-AOT (absolute change [IQR $\times$ (regression estimate/outcome mean)] in $\left.\mathrm{HbA}_{1 \mathrm{c}}:-0.04[-0.04,-0.03]\right)$. The inverse relationship between $\mathrm{O}_{3}$-AOT and $\mathrm{HbA}_{1 \mathrm{c}}$ was stable in sensitivity analyses. Results for annual means of $\mathrm{O}_{3}$ were similar, showing that a decrease in $\mathrm{HbA}_{1 \mathrm{c}}$ was associated with an increment in $\mathrm{O}_{3}$ (Table 2). No robust significant differences in $\mathrm{HbA}_{1 \mathrm{c}}$ in association with $\mathrm{PM}_{10}$ or $\mathrm{NO}_{2}$ were found. We observed no association between any of the air pollutants and insulin dose (data not shown).

Figure 1 shows the association between $\mathrm{O}_{3}$-AOT quartile and $\mathrm{HbA}_{1 \mathrm{c}}$. Lower $\mathrm{HbA}_{1 \mathrm{c}}$ levels were associated with higher $\mathrm{O}_{3}$-AOT quartiles using the main model $\left(\mathrm{Q} 4\right.$, mean $\mathrm{HbA}_{1 \mathrm{c}}$
$63.2 \mathrm{mmol} / \mathrm{mol}$ [62.7, 63.7]; Q1, mean $\mathrm{HbA}_{1 \mathrm{c}} 66.9 \mathrm{mmol} /$ mol [66.3, 67.4]), confirming the inverse association.

The dose-response functions were only examined for $\mathrm{O}_{3}$ AOT and $\mathrm{HbA}_{1 \mathrm{c}}$ and for $\mathrm{O}_{3}$ and $\mathrm{HbA}_{1 \mathrm{c}}$. We observed no deviation from linearity when $\mathrm{O}_{3}$-AOT and $\mathrm{O}_{3}$ were included as a smooth function into the model (ESM Fig. 1).

\section{Discussion}

We investigated the association between long-term exposure to $\mathrm{PM}_{10}, \mathrm{NO}_{2}$ and $\mathrm{O}_{3}$-AOT and indicators of metabolic control in children and adolescents with type 1 diabetes. Our results showed an inverse association between $\mathrm{O}_{3}$-AOT and $\mathrm{HbA}_{1 \mathrm{c}}\left(\mathrm{HbA}_{1 \mathrm{c}}\right.$ decrease of $3.7 \%$ [95\% CI -4.4, -3.0] with an IQR increase in $\mathrm{O}_{3}$-AOT). The observed association could not be explained by differences with respect to various confounders (e.g. Nielsen area or degree of urbanisation [urban and rural areas]). $\mathrm{PM}_{10}, \mathrm{NO}_{2}$ and $\mathrm{O}_{3}$-AOT had no impact on insulin dose and $\mathrm{PM}_{10}$ and $\mathrm{NO}_{2}$ had no impact on $\mathrm{HbA}_{1 \mathrm{c}}$.

Our results showing lower $\mathrm{HbA}_{1 \mathrm{c}}$ with higher $\mathrm{O}_{3}$-AOT exposure are in line with those of a previous analysis of the long-term effects of air pollution from a population-based registry [10]. However, the association found in that study was not robust to all sensitivity analyses performed by the authors [10]. A non-significant inverse association between long-term exposure to $\mathrm{O}_{3}$ and $\mathrm{HbA}_{1 \mathrm{c}}$ was also reported in middle-aged and elderly individuals based on a nationwide cohort in China [11]. Some studies have suggested that $\mathrm{O}_{3}$ has therapeutic effects through a decrease in blood glucose levels, increase in insulin sensitivity and prevention of oxidative stress in individuals with diabetes $[18,19]$. Potential mechanisms involved in the response to $\mathrm{O}_{3}$ have been summarised in a review [19]; especially, animal models support an inverse relationship between $\mathrm{O}_{3}$ and $\mathrm{HbA}_{1 \mathrm{c}}$. For example, treatment with either insulin or $\mathrm{O}_{3}$ was found to significantly reduce $\mathrm{HbA}_{1 \mathrm{c}}$ levels in a rat model of diabetes [20].

In our study, $\mathrm{O}_{3}$-AOT might have been a surrogate for other individual factors which are not controlled for by adjusting for degree of urbanisation, such as physical activity. For example, previous studies reported lower $\mathrm{HbA}_{1 \mathrm{c}}$ levels in association with increased physical activity in children and adolescents with type 1 diabetes $[21,22]$. Another explanation for the inverse association between $\mathrm{O}_{3}$-AOT and $\mathrm{HbA}_{1 \mathrm{c}}$ might be mild haemolysis of erythrocytes [19]. Moreover, trend analyses showed a general decrease in $\mathrm{HbA}_{1 \mathrm{c}}$ in adults and in children and adolescents with type 1 diabetes [23, 24], therefore, the treatment year might also play an important role. However, we adjusted for year of treatment in our analysis. In addition, $\mathrm{O}_{3}$-AOT might be a surrogate for sun exposure and therefore higher vitamin D concentrations (measured as 25hydroxyvitamin $\mathrm{D}[25(\mathrm{OH}) \mathrm{D}])$ might also play a role. Times spent in sunny regions were associated with higher $25(\mathrm{OH}) \mathrm{D}$ 
concentrations in participants of the Cooperative Health Research in the Region of Augsburg, Germany (KORA) F4 survey [25]. Moreover, a significant negative association between 25(OH)D levels and $\mathrm{HbA}_{1 \mathrm{c}}$ values was reported [26].

In our analysis, the inverse association between $\mathrm{O}_{3}$-AOT and $\mathrm{HbA}_{1 \mathrm{c}}$ persisted after additional adjustments for degree of urbanisation and $\mathrm{PM}_{10}$. Hence, the assumption that lower $\mathrm{HbA}_{1 \mathrm{c}}$ with higher $\mathrm{O}_{3}$ concentration in fact reflects differences in diabetes treatment between urban and rural areas is not supported.

In contrast to our results, authors from Southern Israel observed an increase in $\mathrm{HbA}_{1 \mathrm{c}}$ with an IQR increase in average exposure to $\mathrm{PM}_{10}$ over 3 months in individuals with diabetes [9]. However, no association between long-term exposure to $\mathrm{PM}_{10}$ and $\mathrm{HbA}_{1 \mathrm{c}}$ has been reported in other studies $[10,27]$. German authors observed an association between annual means of $\mathrm{PM}_{10}$ and $\mathrm{HbA}_{1 \mathrm{c}}$ in type 2 diabetes [8] but no association in type 1 diabetes [10]. Studies on air pollution and the prevalence and incidence of type 1 diabetes have also produced inconsistent findings [28-30]. Besides other factors, conflicting findings might be due to differences in participant characteristics, individual susceptibility, air pollution sources or exposure misclassification [6]. Methodological differences regarding outcome log-transformation and investigation of linear and non-linear relationships might also play a role. However, in our analysis, results of log-transformed and non-transformed outcomes were similar and we observed no deviation from linearity of the dose-response functions.

The novelty and strength of our study is that we investigated a large-scale, nationwide cohort of children and adolescents with type 1 diabetes whereas previous studies were limited in cohort size or focused on adults with type 2 diabetes. A further strength of our study is the various sensitivity analyses, all showing a robust inverse association between $\mathrm{O}_{3}$ exposure and $\mathrm{HbA}_{1 \mathrm{c}}$ levels. However, our study is limited by the fact that we did not have information on lifestyle, social factors and dietary habits. Moreover, we did not have information on socioeconomic factors such as educational level or household income. Hence, residual confounding cannot be ruled out. Exposure misclassification should be considered, as fivedigit postcodes of place of residence were linked to air pollution data and no information on exposure at school or work was considered. In addition, no information on time spent outdoors was available and background measurements without hotspot stations were used. Air pollution measurements were smoothed using REM-CALGRID model and, therefore, locally higher exposure was not represented.

In conclusion, we observed an inverse association between $\mathrm{O}_{3}$-AOT and $\mathrm{HbA}_{1 \mathrm{c}}$ which remained stable in sensitivity analyses. In our study, the inverse relationship between $\mathrm{O}_{3}$-AOT and $\mathrm{HbA}_{1 \mathrm{c}}$ could not be explained by regional differences in diabetes treatment or by other differences between urban and rural areas. Moreover, our results do not suggest an indirect effect of $\mathrm{O}_{3}$-AOT on $\mathrm{HbA}_{1 \mathrm{c}}$ via an association of $\mathrm{PM}_{10}$ and $\mathrm{HbA}_{1 \mathrm{c}}$. Animal models support our findings. Further studies, especially in other countries, are needed to confirm the association between air pollution and $\mathrm{HbA}_{1 \mathrm{c}}$ in children and adolescents with type 1 diabetes and to elucidate underlying biological mechanisms.

Acknowledgements The authors thank all participating centres of the DPV Initiative, especially those collaborating in this investigation (listed in the ESM). We thank the German Federal Environmental Agency (Umweltbundesamt [UBA], Department II 4.2) for providing the air pollution data.

Data availability The datasets generated during and/or analysed during the current study are not publicly available due to data protection reasons but are available from the corresponding author on reasonable request.

Funding The study was financially supported by the Federal Ministry of Education and Research within the German Competence Network Diabetes Mellitus (grant 01GI1106), which was integrated into the German Centre for Diabetes Research (DZD) as of January 2015. This project has received funding from the Innovative Medicines Initiative 2 Joint Undertaking under grant agreement no. 115797 (INNODIA). This joint undertaking receives support from the Union's Horizon 2020 research and innovation programme and 'EFPIA', 'JDRF' and 'The Leona M. and Harry B. Helmsley Charitable Trust'. Additional support was provided by the German Diabetes Association (DDG). Sponsors were not involved in data acquisition or analysis.

Duality of interest The authors declare that there is no duality of interest associated with this manuscript.

Contribution statement SL contributed to data management, data analysis and manuscript writing and editing. JR contributed to data analysis and manuscript writing and editing. DS and TS contributed to data analysis and manuscript editing. BT, DK and WR reviewed the manuscript and contributed to interpretation of data and manuscript editing. RWH is the principal investigator of the study and contributed to data analysis and manuscript writing and editing. All co-authors approved the final version to be published. RWH is the guarantor of this work and, as such, had full access to all the data in the study and takes responsibility for the integrity of the data and the accuracy of the data analysis.

\section{References}

1. Rao X, Montresor-Lopez J, Puett R, Rajagopalan S, Brook RD (2015) Ambient air pollution: an emerging risk factor for diabetes mellitus. Curr Diab Rep 15:603-015-0603-8

2. Thiering E, Heinrich J (2015) Epidemiology of air pollution and diabetes. Trends Endocrinol Metab 26:384-394

3. Zanobetti A, Schwartz J (2001) Are diabetics more susceptible to the health effects of airborne particles? Am J Respir Crit Care Med 164:831-833

4. Zanobetti A, Schwartz J (2002) Cardiovascular damage by airborne particles: are diabetics more susceptible? Epidemiology 13:588 592

5. Brook RD, Rajagopalan S, Pope CA 3rd et al (2010) Particulate matter air pollution and cardiovascular disease: an update to the scientific statement from the American Heart Association. Circulation 121:2331-2378 
6. Rajagopalan S, Brook RD (2012) Air pollution and type 2 diabetes: mechanistic insights. Diabetes 61:3037-3045

7. American Diabetes Association (2016) Standards of medical care in diabetes-2016. Diabetes Care 39(Suppl 1):1-112

8. Tamayo T, Rathmann W, Kramer U, Sugiri D, Grabert M, Holl RW (2014) Is particle pollution in outdoor air associated with metabolic control in type 2 diabetes? PLoS One 9:e91639

9. Yitshak Sade M, Kloog I, Liberty IF, Schwartz J, Novack V (2016) The association between air pollution exposure and glucose and lipids levels. J Clin Endocrinol Metab 101:2460-2467

10. Tamayo T, Rathmann W, Stahl-Pehe A et al (2016) No adverse effect of outdoor air pollution on HbAlc in children and young adults with type 1 diabetes. Int J Hyg Environ Health 219:349-355

11. Liu C, Yang C, Zhao Y et al (2016) Associations between long-term exposure to ambient particulate air pollution and type 2 diabetes prevalence, blood glucose and glycosylated hemoglobin levels in China. Environ Int 92-93:416-421

12. The European Parliament and the Council of the European Union (2008) Directive 2008/50/EC of the European Parliament and of the Council of 21 May 2008 on ambient air quality and cleaner air for Europe. Available from http://eur-lex.europa.eu/legal-content/EN/ TXT/PDF/?uri=CELEX:32008L0050\&from=EN. Accessed 11 January 2018

13. German Environment Agency (2010) Informationen zum Luftschadstoff Ozon (O3) Available from www. umweltbundesamt.de/sites/default/files/medien/377/dokumente/ infoblatt_ozon.pdf. Accessed 11 January 2018

14. Hofer SE, Schwandt A, Holl RW, Austrian/German DPV Initiative (2016) Standardized documentation in pediatric diabetology: experience from Austria and Germany. J Diabetes Sci Technol 10:10421049

15. Rosario AS, Kurth BM, Stolzenberg H, Ellert U, Neuhauser H (2010) Body mass index percentiles for children and adolescents in Germany based on a nationally representative sample (KiGGS 2003-2006). Eur J Clin Nutr 64:341-349

16. Rosenbauer J, Dost A, Karges B et al (2012) Improved metabolic control in children and adolescents with type 1 diabetes: a trend analysis using prospective multicenter data from Germany and Austria. Diabetes Care 35:80-86

17. Eurostat (2015) Glossary: degree of urbanisation. Available from http://ec.europa.eu/eurostat/statistics-explained/index.php/ Glossary:Degree\%20f\%20urbanisation. Accessed 11 January 2018

18. Martinez-Sanchez G, Al-Dalain SM, Menendez S et al (2005) Therapeutic efficacy of ozone in patients with diabetic foot. Eur J Pharmacol 523:151-161
19. Sagai M, Bocci V (2011) Mechanisms of action involved in ozone therapy: is healing induced via a mild oxidative stress? Med Gas Res 1:29

20. Morsy MD, Hassan WN, Zalat SI (2010) Improvement of renal oxidative stress markers after ozone administration in diabetic nephropathy in rats. Diabetol Metab Syndr 2:29

21. Beraki A, Magnuson A, Sarnblad S, Aman J, Samuelsson U (2014) Increase in physical activity is associated with lower $\mathrm{HbA1c}$ levels in children and adolescents with type 1 diabetes: results from a cross-sectional study based on the Swedish pediatric diabetes quality registry (SWEDIABKIDS). Diabetes Res Clin Pract 105:119125

22. Herbst A, Bachran R, Kapellen T, Holl RW (2006) Effects of regular physical activity on control of glycemia in pediatric patients with type 1 diabetes mellitus. Arch Pediatr Adolesc Med 160:573577

23. Bohn B, Kerner W, Seufert J et al (2016) Trend of antihyperglycaemic therapy and glycaemic control in 184,864 adults with type 1 or 2 diabetes between 2002 and 2014: analysis of real-life data from the DPV registry from Germany and Austria. Diabetes Res Clin Pract 115:31-38

24. Karges B, Rosenbauer J, Kapellen T et al (2014) Hemoglobin A1c levels and risk of severe hypoglycemia in children and young adults with type 1 diabetes from Germany and Austria: a trend analysis in a cohort of 37,539 patients between 1995 and 2012. PLoS Med 11: e1001742

25. Richter K, Breitner S, Webb AR et al (2014) Influence of external, intrinsic and individual behaviour variables on serum $25(\mathrm{OH}) \mathrm{D}$ in a German survey. J Photochem Photobiol B 140:120-129

26. Talaat IM, Nasr A, Alsulaimani AA et al (2016) Association between type 1 , type 2 cytokines, diabetic autoantibodies and 25 hydroxyvitamin D in children with type 1 diabetes. J Endocrinol Investig 39:1425-1434

27. Wolf K, Popp A, Schneider A et al (2016) Association between long-term exposure to air pollution and biomarkers related to insulin resistance, subclinical inflammation and adipokines. Diabetes 65:3314-3326

28. Hathout EH, Beeson WL, Ischander M, Rao R, Mace JW (2006) Air pollution and type 1 diabetes in children. Pediatr Diabetes 7:8187

29. Gonzalez RN, Torres-Aviles F, Carrasco PE, Salas PF, Perez BF (2013) Association of the incidence of type 1 diabetes mellitus with environmental factors in Chile during the period 2000-2007. Rev Med Chil 141:595-601

30. Malmqvist E, Larsson HE, Jonsson I et al (2015) Maternal exposure to air pollution and type 1 diabetes-accounting for genetic factors. Environ Res 140:268-274 